\title{
Cultura hip hop: Batalha dos Bombeiros - entre rimas e reivindicações
}

\author{
Cultura hip hop: Batalha dos Bombeiros - entre rimas y reivindicaciones
}

Hip hop culture: Batalha dos Bombeiros - among claims and rhymes

\author{
Amanda Rosiéli Fiuza e Silva' \\ Sandra Rúbia da Silvall \\ Jonária França da Silva"II
}

Palavras chave:

Cutura

Hip Hop

Periferia

Resistência

Espaço

\section{Resumo:}

Neste artigo descrevo os resultados obtidos através da experiência de uma pesquisa etnográfica intitulada "Batalha dos Bombeiros: elementos da cultura hip hop como ferramenta de resistência sociopolítica". A investigação analisou se a Batalha dos Bombeiros, evento da cultura hip hop da cidade de Santa Maria/RS, pode ser considerado um espaço de representações e reivindicações sociopolíticas. O objetivo foi compreender como e quais são as práticas que auxiliam na construção do caráter de resistência sociopolítica da cultura hip hop na Batalha dos Bombeiros. A metodologia utilizada foi a etnografia e como procedimento metodológico foi realizada a técnica de entrevista individual em profundidade. As observações participantes ocorreram durante cinco meses consecutivos do ano de 2014. E as entrevistas foram realizadas com sete jovens classificados entre organizadores da Batalha dos Bombeiros, integrantes da cultura hip hop e espectadores do evento. A investigação revelou a Batalha dos Bombeiros como cenário de múltiplos significados, isto é, a praça onde são desenvolvidas práticas culturais constitui-se em um espaço simbólico de resistência onde jovens oriundos das periferias da cidade, por meio das expressões culturais e da apropriação do espaço público, manifestam suas lutas sociais e reivindicam melhores condições de vida. Assim, a Batalha dos Bombeiros é um espaço de articulações políticas, vivências e experiências, um legítimo espaço de resistência sociopolítica. 
Resumen:

En este artículo describo los resultados obtenidos a través de la experiencia de una investigación etnográfica titulada "Batalha dos Bombeiros: elementos de la cultura hip hop como herramienta de resistencia sociopolítica". La investigación analizó si la Batalha dos Bombeiros, evento de la cultura hip hop de la ciudad de Santa Maria / RS, puede ser considerado un espacio de representaciones y reivindicaciones sociopolíticas. El objetivo fue comprender cómo y cuáles son las prácticas que auxilian en la construcción del carácter de resistencia sociopolítica de la cultura hip hop en la Batalha dos Bombeiros. La metodología utilizada fue la etnografía y como procedimiento metodológico se realizo la técnica de entrevista individual en profundidad. Las observaciones concurrentes ocurrieron durante cinco meses consecutivos del año 2014. Y las entrevistas fueron realizadas con siete jóvenes que se clasificaron entre organizadores de la Batalha dos Bombeiros, integrantes de la cultura hip hop y espectadores del evento. La investigación revelo la Batalha dos Bombeiros como escenario de múltiples significados, es decir, la plaza donde se desarrollan prácticas culturales se constituye en un espacio simbólico de resistencia donde jóvenes oriundos de las periferias de la ciudad, por medio de las expresiones culturales y de la apropiación del espacio público, manifiestan sus luchas sociales y reivindican mejores condiciones de vida. Así, la Batalha dos Bombeiros es un espacio de articulaciones políticas, vivencias y experiencias, un legítimo espacio de resistencia sociopolítica.

\section{Palabras clave:}

Cultura

Hip Hop

Periferia

Resistencia

Espacio

\section{Keywords:}

Culture

Hip Hop

Periphery

Resistance

Space

\section{Abstract:}

This paper describes the results obtained through an ethnographic research experience entitled "Batalha dos Bombeiros: hip hop cultural elements as a sociopolitical resistance tool". The Batalha dos Bombeiros was analyzed in this investigation, a hip hop culture event in Santa Maria/ $\mathrm{RS}$, it is considered a sociopolitical claim and representation space. The goal was understanding how and which practices assist in character construction of a sociopolitical resistance in hip hop culture in the Batalha dos Bombeiros. Ethnography was used as methodology and individual interview in depth was the methodological procedure utilized. The observation data used dates from the year of 2014 in five consecutive months. Seven Young adults were interviewed, among them were Batalha dos Bombeiros organizers, hip hop culture members and event spectators. The investigation reveals Batalha dos Bombeiros as a multiple meaning scenario, in other words, the square were cultural practices are developed is constituted as a symbol of the resistance were young adults from the suburbs use cultural expression and public space appropriation, manifesting social struggles and claim better living conditions. Therefore, the Batalha dos Bombeiros is a political and experiences articulation space, a legitimate sociopolitical resistance space. 


\section{Cultura hip hop: \\ Batalha dos Bombeiros \\ - entre rimas e reivindicações}

\section{Introdução}

Antes de tudo, iremos trazer a compreensão do que se trata a cultura hip hop. É consenso entre os autores Herschmann (2008; 2005), Coutinho e Araújo (2008), Salles (2007) e Rose (1997) que a cultura hip hop é composta por quatro elementos principais, dentre eles: o grafite, rap, break, Disc Jockey (DJ) ou mestre de cerimônia (MC). Conforme Salles (2007, p.32) "o grafite são pinturas realizadas com tinta spray, sobre as mais variadas superfícies: muros, laterais de trens, painéis [...]".

De acordo com Herschmann (2005) o rap é a expressão musical surgida nos anos 70 nos subúrbios dos EUA, que provém da mistura de vários instrumentos eletrônicos, tais como samplers, mixadores, repentes eletrônicos, entre outros. $\mathrm{O}$ nome rap é a junção das iniciais das palavras que compõe a frase "rythm and poetry", que ao ser traduzido para a língua brasileira significa "ritmo e poesia".

O break é o estilo de dança da cultura hip hop, tendo como características que os movimentos são passos quebrados e robóticos. Conforme Salles (2007), muitos passos dessa dança, surgida nos finais dos anos 1960, foram inspirados pelo contexto da guerra. Assim, foram criados para protestar contra a guerra do Vietnã. Salles (2007, p. 32) aborda que alguns passos "simulavam os movimentos de soldados norte-americanos que retornavam mutilados, outros aludiam a equipamentos usados no conflito".

DJ ou MC eram os responsáveis por animar a festa e também que "selecionam os discos, determinam sua ordem de passagem e seu encadeamento" (SALLES, 2007 , p. 31). Na atualidade, os avanços tecnológicos e o surgimento das mesas de som digitais facilitaram o processo da escolha de discos para seleção das músicas que rodam com auxílio de programa de computadores.

As expressões da cultura hip hop, em grande maioria, são desenvolvidas por jovens oriundos da periferia. Este fator contribui para que esta cultura adquira uma característica de resistência por representar a voz de populações que trazem a tona à realidade social a que estão submetidos os moradores das periferias. Assim, como formas de reivindicação e denúncia social as expressões do hip hop dão visibilidade às questões sociais, denunciam as opressões e violências sofridas por esses jovens e questionam a estrutura social.

Então, buscamos a partir desta pesquisa, compreender quais aspectos de resistência e reivindicações sociais que a Batalha dos Bombeiros promove a partir da relação entre a apropriação do espaço público e as expressões culturais do hip hop no espaço do evento. Desta forma, a investigação consistiu em analisar a cultura hip hop e entender os mecanismos de comunicação e reivindicações sociais expressadas pelos jovens do hip hop na cidade de Santa Maria/RS, especificamente, no âmbito da Batalha dos Bombeiros.

A Batalha dos Bombeiros é um evento da cultura hip hop de Santa Maria/ RS que é realizado desde o ano de 2012 na cidade. A Batalha dos Bombeiros foi idealizada e é organizada pelo Coletivo de Resistência Artística Periférica (CO-RAP). Este evento ocorre esporadicamente, toda segunda sexta-feira do mês, na Praça Menna Barreto, espaço público central da cidade, popularmente conhecida como "Praça dos Bombeiros". A Bata- 
Iha dos Bombeiros consiste em duelos de rimas feito à capelalv. No evento, vários rappers ou MCs da cidade se enfrentam numa disputa de rimas improvisadas. $O$ vencedor é o rapper que conseguir construir melhor suas rimas e cativar o público presente, que atua como juiz, escolhendo o vencedor de cada duelo. Em agosto de 2017, a batalha completou cinco anos de existência, apesar de já ter ocorrido em outros locais da cidade, tais como Diretório Central de Estudantes (DCE) da Universidade Federal de Santa Maria (UFSM) e Parque Itaimbé, todavia eram eventos isolados que não ocorriam com determinada frequência.

Esta investigação tratou a Batalha dos Bombeiros como um expoente do movimento hip hop na cidade. A motivação surgiu frente ao cenário cultural da cidade, pois apesar de Santa Maria ser considerada "Cidade Cultura", as manifestações artísticas oriundas das periferias não são valorizadas, tampouco recebem espaço na agenda cultural da cidade. Percebemos que a abertura de espaços para a cultura hip hop costuma ser negligenciada. A maioria dos eventos da cultura hip hop realizados na cidade costumam ser organizados e desenvolvidos pelos próprios jovens sem apoio do poder público.

Então, tendo em vista o contexto cultural da cidade de Santa Maria e os fatores que estão relacionados à cultura hip hop, a pesquisa foi importante para compreender como se constrói o caráter de comunicação alternativa e todo o processo de resistência sociopolítica que envolve o movimento hip hop na ambiência da Batalha dos Bombeiros. Além disso, esta investigação permite desmistificar a visão estigmatizada da cultura hip hop, mostrando que os jovens das periferias têm consciência política e sabem encontrar modos de atuar perante um sistema opressor que a todo custo tenta abafar as vozes da periferia.
Para tanto, o enfoque que norteou todo o percurso da investigação científica consistiu em entender como é construído o aspecto de resistência sociopolítica da cultura hip hop de Santa Maria, através da análise etnográfica da Batalha dos Bombeiros. Dessa forma, o objetivo principal foi investigar quais são as práticas que auxiliam na construção do caráter de resistência sociopolítica da cultura hip hop na Batalha dos Bombeiros. Almejamos entender de que forma neste cenário de relações conflituosas, entre privilegiados e desfavorecidos, que a cultura hip hop atua como forma de representação social e reivindicação sociopolítica, intervindo, através das expressões culturais, por meIhores condições sociais.

\section{A cultura das periferias: o hip hop como comunicação e resistência}

Nossas discussões compreendem três perspectivas: comunicação alternativa, apropriação de espaço público e cultura hip hop,as quais são relevantes para entendermos como e porque a cultura hip hop pode ser compreendida como uma ferramenta de comunicação e resistência sociopolítica. Precisamos, antes de tudo, refletir acerca do contexto de surgimento e trajetória da cultura hip hop para que seja possível compreender seu caráter de resistência sociopolítica. Do mesmo modo, percebermos como as expressões culturais do hip hop podem se constituir como forma de comunicação alternativa frente ao sistema de comunicação dominantev. Por fim, a questão de apropriação de espaço público é imprescindível devido ao fato da Batalha dos Bombeiros acontecer numa praça central da cidade e promover elementos da cultura urbana advinda das periferias.

A cultura hip hop, segundo Coutinho e Araújo (2008), tem sua origem em 
um contexto conturbado. Surgiu em meados dos anos 1960/1970 nos Estados Unidos da América (EUA), em meio ao auge da Guerra Fria. O contexto local era de descontentamento devido às perturbações causadas pela guerra. Além disso, nessa época, as comunidades negras viviam submetidas a leis severas, que eram aplicadas com o objetivo de manter um processo de segregação, fazendo com os negros se mantivessem restritos aos seus subúrbios. A situação dos guetos, além da precariedade estrutural, era de insatisfação e clima tenso, um ambiente propício para revolta.

Rose (1997) aborda que foi justamente a desordem estrutural que impulsionou os jovens dos subúrbios a encontrarem alternativas de lazer frente ao caos e precariedade que vivenciavam no cotidiano. Assim, de forma isolada os elementos do movimento hip hop estavam sendo desenvolvidos. Nas letras de rap os jovens expressavam suas inquietações sociais, faziam críticas ao sistema e revelavam suas experiências de vida, cercadas de violência, repressão e pobreza.

O hip hop acabou se constituindo como uma cultura de resistência pelo fato que a partir dos elementos culturais os jovens expressavam suas críticas e denúncias. Dessa forma, notamos que as expressões culturais do hip hop são mecanismos alternativos de comunicação dos jovens dos subúrbios e periferias, pois revelam a estrutura social opressora que promove e mantém as desigualdades sociais.

Como bem explana Coutinho (2008), os moradores de periferia constroem estratégias de expressão para fugir dos mecanismos de repressão social. Estas estratégias são denominadas pelo autor de "rotas de comunicação alternativa", pois são as maneiras que os moradores encontram de terem voz e adquirirem visibilidade para suas reivindicações sociais.

Ao contrário do que se costuma imaginar, se não ouvimos a fala política dos habitantes das favelas - e mesmo dos moradores de rua - não é porque eles estejam anestesiados, passivos ou não tenham nada a dizer: é porque sua voz é calada, abafada, distorcida (COUTINHO, 2008, p.65).

Conforme Coutinho (2008) as "rotas de comunicação alternativa" são os caminhos alternativos que a população periférica encontra para fugir dos mecanismos de coerção hegemônica. Para o autor, o sistema sempre encontra modos de silenciar a voz da população periférica, isto é, através de mecanismos de controle social tenta fazer com que a voz da periferia não seja escutada. Nesta perspectiva, as "rotas de comunicação alternativa" são justamente os meios que as pessoas, moradoras das comunidades periféricas, encontram de "burlar" esse sistema opressor e dar voz às suas reivindicações.

As expressões da cultura hip hop são desenvolvidas a partir das percepções que os jovens têm da sociedade, sendo formas de agir sobre a realidade vivenciada, constituindo-se em importantes ferramentas de denúncia e transformação social. Para Coutinho (2008), a cultura hip hop é uma forma de expressão que desmascara o "mito da sociedade democrática", a partir do momento que expõe as desigualdades sociais, as mazelas das comunidades periféricas, as diferenças de oportunidades e tratamento dado aos moradores da periferia. Herschmann (2005, p. 38), complementa "regime democrático que, mesmo reinstalado desde a década de 80 , não conseguiu concretizar efetiva- 
mente a cidadania nem oferecer melhores condições de vida".

Pela razão de a Batalha dos Bombeiros ocorrer em espaço público localizado na região central da cidade de Santa Maria e a cultura hip hop ser um elemento representativo das comunidades periféricas, a construção da resistência sociopolítica neste local precisou ser entendida também pela lógica da apropriação de espaço público da cidade.

Magnani (2000; 2012) contribui no diálogo sobre apropriação de espaço público. O autor utiliza a expressão "pedaço" para designar o espaço que os grupos utilizam para construir novas relações sociais diferentes das estabelecidas no ambiente da comunidade de origem, visto que neste caso as relações na sua maioria são parentais, constituindo "novos arranjos sociais". Além disso, segundo o autor esse "pedaço" também é utilizado pelos grupos para a prática de atividades de lazer ou até mesmo como um espaço para discussões e debates, em que os jovens, através da construção de novas redes de sociabilidade constroem e obtém visibilidade para suas reivindicações.

Borja e Muxí (2000) percebem os espaços públicos como lugares de múltiplas significações, constituindo-se em espaços físicos, simbólicos e políticos, isto é, como lugares de representação em que a sociedade fica visível. Para Borja e Muxí (2000), os espaços públicos são os suportes que possibilitam aos cidadãos realizarem as manifestações populares e movimentos sociais.

Ainda, Borja e Muxí (2000) afirmam que o espaço público é um direito de primeira ordem "assim o espaço público deve garantir em termos de igualdade o direito à apropriação de diferentes coletivos sociais e culturais, de gênero e de idade" (BORJA; MUXÍ, 2000, p.11, tra- dução nossa). Sendo assim, segundo os autores, o espaço público seria o lugar de representação e expressão de todos os cidadãos, onde a cidadania é efetivada.

Compreendemos que a apropriação do espaço é uma prática que traz outro significado àquele local, isto é, é uma prática simbólica que tem haver com o uso que os sujeitos fazem dos espaços. A apropriação dos espaços públicos promove encontros e trocas bem como põe em conflito as contradições da sociedade. A apropriação do espaço público para práticas de eventos culturais ou até mesmo de lazer propicia que o espaço urbano, na maioria do tempo um espaço de passagem, constitua-se em um "pedaço" onde a vida cotidiana transcorre, onde os grupos coexistem e onde o encontro acontece. É no espaço público que as relações de desigualdades e as diferenças são postas em contato e as tensões acontecem.

Dessa forma, os espaços públicos são lugares de sociabilização e resistência. A ocupação desses locais é uma das alternativas que os jovens encontraram para enfrentar os mecanismos de segregação e "enclausuramento" que as políticas de desenvolvimento de infraestrutura das cidades criam. Os jovens, através de suas culturas juvenis, buscam resistir e utilizar esses espaços para reivindicar seus direitos enquanto cidadãos.

\section{Metodologia}

No que se refere à metodologia de pesquisa, estivemos amparadosna etnografia devido ao fato que as inserções em campo dão a possibilidade de explorar o universo do fenômeno pesquisado. Segundo Caiafa (2007, p. 139), a pesquisa etnográfica "leva em conta toda a profusão das impressões e informações que espocam nos encontros em campo". En- 
tão, através da observação participante adentramos no campo da pesquisa para analisar o fenômeno estudado e ainda tivemos a possibilidade de vivenciar novas experiências, uma vez que "a experiência em campo é talvez o aspecto mais marcante e definidor da pesquisa etnográfica [...]" (CAIAFA, 2007, p. 147).

Além da observação participante como procedimento metodológico utilizamos a técnica de entrevistas individuais em profundidade, com base em Duarte (2005). Segundo este autor, a entrevista em profundidade "é uma técnica qualitativa que explora um assunto a partir da busca de informações, percepções e experiências de informantes para analisá-las e apresentá-las de forma estruturada" (DUARTE, 2005, p. 62). Conforme o autor, essa modalidade possibilita que o entrevistador tenha maior liberdade para conduzir a entrevista de acordo com suas intenções, ajustando as perguntas às necessidades informacionais da pesquisa ao mesmo passo que o informante tem livre arbítrio de responder utilizando sua própria linguagem, ou seja, sem precisar utilizar termos que não são sejam de seu conhecimento.

Assim sendo, estivemos imersas em campo durante cinco edições da Batalha dos Bombeiros, mais especificamente, na $21^{a}, 22^{a}, 23^{a}, 24^{a}$ e $25^{a}$. Ocorridas respectivamente nos meses de Junho, Julho, Agosto, Setembro e Outubro do ano de 2014, sempre na segunda sexta-feira do respectivo mês. Nessas inserções contamos com o auxílio do diário de campo no qual fizemos anotações referentes às observações, as reflexões surgidas a partir de alguns acontecimentos, percepções obtidas por meio de conversas, entre outras coisas, tais como registros fotográficos.

Em relação às entrevistas foram realizadas sete ao total. Inicialmente es- tavam previstas dez, mas devido à recusa de alguns representantes de outros coletivos, foram concretizadas apenas sete. Estas entrevistas foram realizadas com a intenção de obter informações que fossem relevantes à investigação e pudessem embasar as observações adquiridas em campo. Devido à necessidade de uma abordagem que contemplasse três perspectivas diferentes, considerando os múltiplos públicos que estão envolvidos no ambiente da Batalha, as entrevistas foram divididas nas seguintes categorias: 1) Espectadores 2) Organizadores e 3) Membros da cultura hip hop. Sendo assim, foram realizadas as seguintes entrevistas: quatro com representações dos membros da cultura hip hop, dois representantes do grupo de espectadores e um representante do coletivo organizador da Batalha.

No critério de seleção dos entrevistados buscamos por membros de coletivos da cultura hip hop que participam da Batalha dos Bombeiros, para entender como os diferentes membros da cultura e das várias regiões da cidade de Santa Maria percebem a Batalha, captando, assim, sob vários vieses as percepções sobre o fenômeno estudado. Na escolha dos espectadores selecionamos os que notamos mais seguidamente no evento, ou seja, que tivessem comparecido em pelo menos duas edições da Batalha. Já na questão do representante do coletivo que organiza a Batalha dos Bombeiros, CO-RAP, a escolha ficou a critério interno do próprio coletivo.

Sendo assim, as entrevistas foram realizadas individualmente e com auxílio do gravador do celular, posteriormente, foram transcritas. Por se tratarem de entrevistados de categorias diferentes o questionário foi organizado com perguntas em comum e perguntas específicas para cada grupo de informantes. As informações coletadas nessas entrevistas 
foram importantes para entendermos a percepção e importância da Batalha dos Bombeiros através de três pontos de vista diferentes, isto é, membro da cultura hip hop, organizadores e espectadores. Pretendíamos a partir disso, analisar a existência de percepções em comum, mas também de reflexões e desdobramentos diversificados que ampliassem o escopo da pesquisa.

\section{Batalha dos bombeiros: espaço de conflitos e negociações}

Primeiramente, cabe ressaltar que os resultados apresentados perpassam dois aspectos importantes que estão relacionados no ambiente da Batalha dos Bombeiros, para efeitos de análise podem ser tratados da seguinte forma: 1) ocupação do espaço público central e 2) elementos da cultura hip hop presentes na Batalha dos Bombeiros. Por essa razão, os relatos tratam sobre a ocupação do espaço central e o que este fator contribui para o aspecto de resistência sociopolítica e, além disso, para a própria cultura hip hop. Além disso, abordam os elementos da cultura hip hop encontrados na Batalha dos Bombeiros e como eles são utilizados pelos membros para manifestarem suas reivindicações sociais.

Para compreender como o ambiente da praça é transformado em cenário de resistência e manifestações sociopolíticas e ganha características da comunidade periférica,chegávamos uma hora antes e permanecíamos no local por mais uma hora após o evento. Esta permanência em campo de estudo possibilitou visualizarmos o ambiente da praça antes e após a da Batalha dos Bombeiros, percebendo como a praça iria aos poucos sendo transformada em espaço de representações e manifestações sociopolíticas. Neste sentido, através da observação participante notamos que a ocupação do espaço público central para a realização da Batalha dos Bombeiros (re)significa a Praça Menna Barreto trazendo para este local características/símbolos típicos da comunidade periférica, além disso, transforma aquele "pedaço" (MAGNANI, 2003) em um verdadeiro espaço de representações e manifestações sociopolíticas.

\subsection{Ocupar é resistir: a apropriação e ressignificação da Praça.}

Percebemos que a ocupação da Praça Menna Barreto, localizada em espaço central da cidade, dá voz a tensões e conflitos, pois promove o encontro de diferentes classes sociais. Neste sentido, a prática de ocupar o espaço tornando-o "palco" de expressões artísticas oriundas da periferia torna visíveis as diferenças e expõe as desigualdades sociais. A ocupação por jovens advindos dos bairros e comunidades é o primeiro aspecto que ressignifica o espaço, antes ocupado por jovens e senhoras de classe média moradores dos entornos da Praça.

De fato, a transformação simbólica do espaço começa a ser constituída quando os integrantes do CORAP estendem o varal de bandeiras entre as árvores da praça. Assim, o cenário de resistência e representação da comunidade periférica vai aos poucos sendo composto pela expressão estética da cultura hip hop, representado através das bandeiras com desenhos feitos à tinta, spray ou até mesmo com a técnica do stencil. As bandeiras trazem algumas reivindicações sociais dos membros da cultura hip hop, seus conteúdos são diversificados, desde frases, tais como "Perigo! Rede Globo aliena", quanto a imagens que referenciam militantes de outras épocas, como a caricatura de Che Guevara. Além disso, o banner com a logo do CO-RAP está exposto no local como afirmação da identidade periférica do coletivo. 


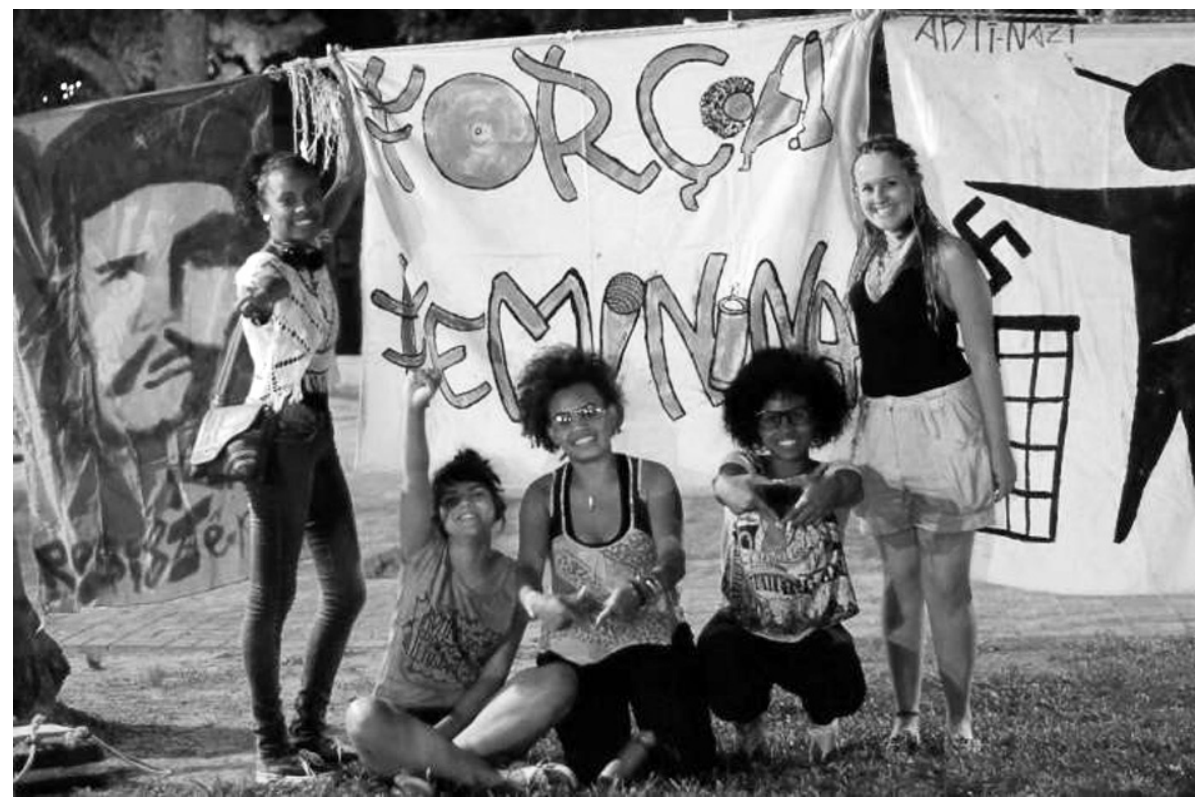

Figura 1: Bandeiras expostas na Batalha e representantes do CO-RAP.

Fonte: FACEBOOK DO CO-RAP. DISPONIVEL EM <https://www.facebook.com/corapsm>.

Gabriela da Silva, representante do CO-RAP, ao explicar a utilização das bandeiras afirma que são usadas para demarcação de espaço, pois demonstram os coletivos presentes no evento e algumas das reivindicações sociais que fazem parte das lutas do movimento. Ela cita três exemplos para corroborar as suas percepções, assim como: a presença da bandeira das mulheres, as bandeiras formadas por $\mathrm{crew}^{\mathrm{XI}}$ e a bandeira que reivindica a questão da mídia. Continuando suas reflexões, ela afirma que a exposição das bandeiras cria novo aspecto ao ambiente da praça, isto é, através da criação de novo arranjo espacial, faz com que os membros da cultura se sintam em ambiente familiar, ou seja, imprime características da cultura hip hop e das comunidades periféricas para aquele local.

Lucas Santiago, espectador, acredita que através da Batalha consegue ver a representação da periferia que é o "local onde tem cultura negra, tem cultura hip hop, tem vários elementos que tu não encontra em festas comuns no centro da cidade". O entrevistado menciona que a Batalha possibilita que a periferia ocupe os espaços centrais da cidade, trazendo seus elementos para esses locais, sua cultura, os elementos do hip hop, possibilitando que diferentes públicos conheçam mais sobre a cultura de resistência e até sobre a própria periferia.

Ao questionar os entrevistados sobre a ocupação do espaço público central e o que este fator acrescenta para a realização da Batalha dos Bombeiros e para cultura hip hop, também obtivemos respostas as quais ajudaram a compreender que a utilização da praça auxilia na fortificação da cultura hip hop e das suas relações de produção e consumo. $O$ informante Rafael Menezes, membro do coletivo Rima Suprema, respondeu que a Batalha ajuda a fortificar a cultura hip hop a qual estava um pouco enfraquecida na cidade e, além disso, serve como um painel, isto é, um espaço onde os MCs podem mostrar seu trabalho para os diferentes públicos que frequentam o evento. 
Segundo ele, através da Batalha as pessoas têm a oportunidade de conhecer o trabalho dos MCs, que são em sua maioria produções independentes, e, caso gostem, podem se tornar compradoras dessas criações.

Sendo assim, pode-se dizer que a Batalha é um espaço onde o circuito de produções independentes se mantém e fortalece. Além disso, um espaço onde são construídas novas redes de sociabilidade, fortalecimento das relações sociais e da própria cultura hip hop. Assim como confirma Cauê Jacques, membro do coletivo Nova Beat, falando que foi através da Batalha dos Bombeiros que conheceu $70 \%$ dos MCs da cidade. Ele contou que antes do evento não conhecia as pessoas que participavam da Batalha. Em sua concepção, a Batalha foi um "divisor de águas" para falar sobre a unificação da cultura hip hop, principalmente do elemento rap, pois menciona o fato de que antes da Batalha os MCs faziam os sons isolados nos seus bairros.

As respostas obtidas ajudaram a refletir sobre o que afirma Souza (2012) ao abordar a relação do rapper com a comunidade, afirmando que existem redes de sociabilidades dentro da comunidade, mas que para fortificar a cultura hip hop é preciso construir novas redes fora desse ambiente. Segundo esta perspectiva, a Batalha dos Bombeiros é um espaço que oportuniza aos rappers a criação de novas redes de sociabilidade e, dessa forma, possibilita a ampliação do campo de visibilidade das criações culturais para além das comunidades de origem.

Já a informante Gabriela Marques, membro do coletivo CO-RAP, menciona que a utilização do espaço central possibilita o conhecimento sobre a cultura hip hop e até mesmo que esta seja menos discriminada. Os membros da cultura têm a oportunidade de mostrarem o que carac- teriza a cultura hip hop para os habitantes da região central da cidade. Gabriela da Silva, representante do CO-RAP, corrobora afirmando que a Batalha dos Bombeiros é favorável para demonstrar que nas comunidades periféricas também existe cultura e outros aspectos positivos.

Lucas Santiago, espectador, menciona que o evento auxiliou no aprofundamento de seus conhecimentos sobre a cultura hip hop, cita que aprendeu que existem várias vertentes e formas de atuação e de luta do movimento. O entrevistado complementa falando que a Batalha auxilia na conexão de diferentes segmentos da sociedade e possibilita a interação e integração de vários movimentos sociais, auxiliando na quebra de certos preconceitos.

[...] eu acho que a interação entre os grupos é essencial para a convivência, que eles convivam assim pra não segregarem espaços onde eles não possam se conhecer e quebrar certos preconceitos, assim. Agora mesmo na última Batalha teve o Coletivo Voe que pode fazer uma intervenção, uma aula pública antes da Batalha dos Bombeiros, né, trazendo até as discussões do movimento LGBTT's pra Batalha, então isso já vai ser duas culturas, duas resistências que vão tá convivendo e se desenvolvendo junto. (Lucas Santiago, frequentador da batalha, 2014).

Neste sentido, a própria ocupação do espaço público central para realização da Batalha dos Bombeiros que promove e fortifica a cultura de rua é um ato de enfrentamento aos mecanismos criados pelo sistema para o confinamento e segregação dos moradores da periferia aos espaços da comunidade, isto é, essa ruptura que ocorre quando o espaço central é ocupado se configura em uma forma de resistência sociopolítica. 
A fala de Gabriela da Silva, representante do CO-RAP, contemplou as minhas percepções acerca da Batalha, visto que a informante concebe a BataIha dos Bombeiros como um espaço de fortalecimento da juventude, pois são os jovens que estão construindo e (re)significando aquele espaço. Para, além disso, a informante afirma que é neste local que os jovens têm espaços para mostrar suas demandas.

\section{[...] mostrar as demandas que a ju- ventude periférica e não periférica têm, que é esse anseio, essa fome por cultura, essa fome do que fazer, sabe. Então, eu acho que vem mos- trando isso tanto para os represen- tantes do poder público da nossa cidade, que já não enxergam perife- ria lá na periferia e ali talvez é uma maneira que consigam enxergar [...] é uma outra maneira de tá ocupando e de tá mostrando quem a gente é (Gabriela da Silva, representante do CO-RAP, 2014).}

Então, as inserções em campo permitiram considerar que a representação da comunidade periférica se dá, principalmente, através de dois aspectos: através da presença de jovens moradores da periferia e dos elementos da cultura hip hop estruturados naquele espaço. A presença dos jovens representa o povo da comunidade, já as expressões artísticas representam a cultura da periferia, muitas vezes utilizadas como forma de comunicação perante um sistema que oprime a voz das comunidades. Assim como nos afirma Coutinho (2008), ao falar que a voz falada ou cantada é uma das poucas formas de expressão utilizadas pelos moradores das comunidades que os mecanismos de opressão não podem silenciar. Neste sentido, o espaço da batalha oportuniza que as demandas da juventude sejam escutadas e que através das expressões culturais os jovens desenvolvam certa autonomia para enfrentar e participar ativamente das lutas sociais necessários para transformação da sociedade.

4.2 Os elementos da cultura periférica como forma de resistência sociopolítica

A cultura hip hop ou organização sociocultural (SALLES, 2007) é composta por várias expressões artísticas. Através das inserções em campo observamos quais elementos estão presentes na Batalha dos Bombeiros. Então, analisamos se esses elementos expressam reivindicações sociais ou trazem questões sociais para debate.

$\mathrm{Na}$ Batalha dos Bombeiros, percebemos que o aspecto de resistência sociopolítica da cultura hip hop é feito através da rima freestyle ${ }^{\mathrm{VII}}$ e da utilização de grafitagens, porém, o elemento break não aparece na Batalha. As bandeiras são os elementos utilizados para representar o grafite, todavia, não existe a técnica de grafitagem ao vivo. Gabriela Marques, membro do coletivo CO-RAP, durante a entrevista ao ser questionada sobre o não aparecimento do break, menciona ter conhecimento de Batalhas em outras cidades, cita a Batalha de Belo Horizonte, que misturam dança e rima. Todavia, a informante afirma que a Batalha dos Bombeiros tem por objetivo reforçar o movimento de origem da cultura hip hop, a qual surgiu por meio das rimas freestyle. Então, Gabriela acredita que essa opção de formato foi mais por uma questão cultural.

Ao analisar as temáticas das rimas pronunciadas na Batalha notamos que estas expressam reivindicações e críticas variadas, isto é, cada $M C$ revela suas experiências de vida e num contexto geral criticam o sistema social. Neste sentido, as rimas falam sobre a realidade e a vivência nos bairros e comunidades periféri- 
cas, a exclusão social, a violência policial, preconceito, elementos da cultura hip hop, motivações e inspirações para compor e sobre o fato de estarem ocupando aquele espaço, isto é, sobre a inserção num local diferente de sua "quebrada".

O informante Telles Rodrigues, espectador, aborda sobre a diferença dos raps escutados através da mídia e os que são pronunciados pelos $M C s$ na Batalha. Desse modo, o entrevistado fala que os raps vistos nos meios de comunicação são banais e não contemplam a realidade das ruas e das periferias. Por outro lado, na Batalha dos Bombeiros, ele escuta rimas que problematizam as questões de desigualdade social, preconceito, violência, entre outras coisas do cotidiano. O informante complementa dizendo que esse tipo de rima contemplou as suas percepções acerca da realidade do cotidiano e das comunidades periféricas.

Então, apesar das rimas terem temáticas variadas os MCs demonstram bastante preocupação em exercer sua função social e representar a comunidade, ou seja, como denomina Salles (2007) "ser um mediador entre a favela e a sociedade no geral" (SALLES, 2007, p.47). Conforme Herschmann (2005) "os jovens se apresentam como espelhos do seu tempo de uma realidade próxima, mas nem sempre visível, promovendo novas formas de integração social que se configuram em territorialidades, diferenças e tensões presentes no tecido urbano" (HERSCHMANN, 2005, p. 230). Sendo assim, é muito importante que os MCs atuem como representantes dos seus bairros/comunidades para apresentá-los de forma realista, com seus aspectos negativos e positivos, pois na maioria das vezes são invisibilizados ou apresentados apenas pelo viés negativo pela mídia hegemônica. Como confirma Souza (2012), exemplificando a partir da análise dos bairros de Florianópolis, Santa Catarina, o processo de invisibilidade ou até mesmo de estigmatização dos bairros periféricos, ao relatar que "alguns bairros precisam ser ressignificados na sua relação com a cidade por serem invisibilizados ou negativados nas representações" (SOUZA, 2012, p.103).

As entrevistas também revelaram essa preocupação dos membros da cultura hip hop em utilizarem as expressões culturais de forma responsável. Matheus Almeida, membro do coletivo Nova Beat, percebe a cultura hip hop como uma ferramenta de mudança social, em que as expressões devem ser construídas de acordo com a mensagem a ser passada, isto é, a crítica deve sempre estar presente nas canções/músicas. A partir disso, para ele os rappers têm a responsabilidade de utilizarem as expressões culturais como mecanismos de ação política, que além de criticarem o sistema, atuem de forma a conscientizar as pessoas; posteriormente, essa conscientização levará à transformação social. Dessa forma, Matheus, compreende a cultura hip hop como um dispositivo de revolução social.

$\mathrm{Na} 24^{\mathrm{a}}$ edição, antes do começo da Batalha, ocorreu o lançamento do projeto Biblioteca de Rua. Segundo Matheus Almeida, um de seus idealizadores, este projeto visa levar o conhecimento, que para ele é o quinto elemento da cultura hip hop, aos moradores da periferia, distribuindo informação através da literatura marginal. Através desse projeto alguns livros, todos conseguidos através de doações, são disponibilizados para os frequentadores da Batalha, estes podem pegar o livro que quiserem e ficar até a próxima edição do evento.

Busquei entender a percepção política dos membros da cultura hip hop e do público frequentador do evento 
para analisar se eles percebem as expressões culturais presentes no evento como formas de atuação sociopolítica. Dessa forma, em relação às percepções do público frequentador, ou seja, aquelas pessoas que não fazem parte de nenhum coletivo da cultura hip hop na cidade, busquei saber o que eles consideram atuação política e se conseguem visualizar a Batalha como espaço de expressões sociopolíticas. Telles Rodrigues, espectador, acredita que a Batalha tem cunho totalmente político, seja através das rimas, da ocupação do espaço ou das intervenções que ocorrem naquele local. Ele acrescenta falando que a política não é essa que o estado realiza, renega este tipo, abordando que a política para ele é o povo quem faz. Para, além disso, Telles faz um contraponto entre prática e teoria para explicar que a política é esse enfrentamento, as vivências sofridas dos moradores de periferia, não leem sobre os assuntos, tais como violência, mas sim sofrem violência.

Lucas Santiago, espectador, corrobora ao afirmar que a Batalha auxilia na desconstrução de ideia de política na cabeça da juventude. $O$ entrevistado aborda sobre a ideia senso comum de política, sempre aliada ao político ladrão e as questões de divulgação de campanha. Exemplifica falando que a própria autonomia do coletivo organizador da Batalha em não ter uma caixa de som e não pedir auxílio à administração municipal já é um ato político.

No que se refere ao entendimento dos entrevistados que são membros de coletivos da cultura hip hop sobre política e as percepções deles sobre a Batalha dos Bombeiros como espaço onde se perpetuam práticas de resistência sociopolítica, a maioria renega a política tradicional, todavia, eles têm consciência do espaço da Batalha ser um local oportuno para perpetuar as ideologias e demandas da comunidade periférica. Rafael Menezes, membro do coletivo Rima Suprema, disserta que não se envolve com política, menciona o fato de ir votar porque é uma obrigação. Cauê Jacques, membro do Nova Beat, diz que a maioria dos MCs são contra os políticos, pois acham que são todo corruptos, além disso, menciona que as rimas expressam essa falta de empatia com a política tradicional e com os políticos. No entanto, ele entende que a política é uma coisa do cotidiano e compara o movimento hip hop às siglas dos partidos políticos, falando que a cultura hip hop é bem mais forte, pois tem proporções mundiais.

Gabriela da Silva, representante do CO-RAP, argumenta que a Batalha é um espaço de expressões e manifestações sociopolíticas, mas que, todavia, esse aspecto precisa ser mais aproveitado. A entrevistada traz um relato para exemplificar, falando da $25^{a}$ edição da Batalha dos Bombeiros, a qual aconteceu poucos dias antes da votação eleitoral, dialoga sobre o fato de quase ninguém ter mencionado as eleições, diz que apenas um $M C$ referenciou sobre a importância de votar certo. A jovem relata que nesse momento uma pessoa da plateia gritou "Vamos de Dilma" e que o $M C$ não se posicionou e ainda expressou que não estava fazendo apologia política. Gabriela acredita que esta seria uma estratégia de atuação política, devido ao fato de ter bastante público presente. Desse modo, a entrevistada compreende que muitas pessoas ainda não percebem o potencial expressivo do movimento hip hop e toda força de atuação e resistência sociopolítica que caracteriza a cultura como combativa. A entrevistada completa dizendo que parece existir certa resistência, infelizmente, da maioria do povo das periferias em querer ser politizado. 


\section{Considerações}

Neste artigo relatamos os resultados obtidos por meio das observações de participantes,através da experiência etnográfica realizada na Batalha dos Bombeiros, abordando as estratégias utilizadas pelos integrantes do hip hop neste espaço para criar suas reivindicações sociopolíticas através das expressões culturais do hip hop. Então, direcionando as investigações para o ambiente da Batalha dos Bombeiros, percebemos que a ocupação da praça central para realização do evento cultural do hip hop torna-se um ato de resistência a partir do momento que os jovens advindos da periferia ressignificam o aspecto da praça, trazendo para este local, elementos característicos da cultura hip hop e das comunidades periféricas, transformando a praça em espaço de articulações políticas, vivências e experiências.

Os integrantes da cultura hip hop desenvolvem, no espaço da Batalha dos Bombeiros, práticas culturais que auxiliam nas reivindicações sociais, nas interações sociais, na manutenção e fortalecimento da cultura hip hop. Percebemos que as expressões culturais do hip hop são também formas de atuação política e de resistência social perante um sistema que promove e mantém as desigualdades.

Neste sentido, conseguimos conceber a Batalha dos Bombeiros como um espaço de expressões sociopolíticas que permite compreendermos que as formas de atuação política não se realizam e se constroem apenas nos espaços governamentais, mas que as práticas políticas podem ser desenvolvidas cotidianamente e, principalmente, através da cultura. Além disso, auxiliou-nos para desmistificar a imagem que a sociedade tem dos moradores de comunidades periféricas, apresentando aspectos positivos do âmbito das comunidades e também revelando que os sujeitos moradores destes locais têm formas de organização e articulação política, as quais foram reveladas nesta pesquisa através das expressões artísticas da cultura hip hop no âmbito da BataIha dos Bombeiros.

Todavia, também é perceptível que, apesar de todas as práticas de resistência reafirmadas no espaço da Batalha, seja através das rimas ou até mesmo da própria ocupação e (re)significação do espaço, ainda existe a necessidade do amadurecimento em relação ao conceito de atuação política de alguns membros da cultura hip hop de Santa Maria/RS, para que estes consigam aproveitar todo o potencial que o espaço da Batalha oferece como local onde as lutas sociais e o enfrentamento aos mecanismos de poder podem ser construídas.

\section{Bibliografia}

ARAÚJO, Marianna; COUTINHO, Eduardo Granja. Hip hop: uma batida contra-hegemônica na periferia da sociedade global. In: Anais do XXI Congresso Brasileiro de Ciências da Comunicação, Natal, 2008. Disponível em: <http://www.intercom.org.br/ papers/nacionais/2008/resumos/R3-0870-1. pdf>. Acesso em 15 de março de 2014.

BORJA, Jordi; MUXI, Zaida. El espacio Público: ciudad e ciudadania. Barcelona: Electra, 2003.

CAIAFA, Janice. Aventura das cidades: ensaios e etnografias. Rio de Janeiro: Editora FGV, 2007.

CASTRO, L. R. Os jovens podem falar? Sobre as possibilidades políticas de ser jovem. In: DAYRELL, J; MOREIRA, M. I. C; STENGEL, M. (orgs.). Juventudes contemporâneas: um mosaico de possibilidades. Belo Horizonte: Ed. PUCMINAS, 2011. p. 43-67. 
CATANI, A. M; GILIOLI. R. S. P. Culturas juvenis: múltiplos olhares. São Paulo: Editora UNESP, 2008.

COSTA, R. S. Uma experiência com autoridades: pequena etnografia de contato com o hip hop e a polícia num morro carioca. In: VELHO, Gilberto.; KUSCHNIR, K. (orgs.). Pesquisas urbanas: desafios do trabalho antropológico. Rio de Janeiro: Jorge Zahar, 2003. p. 139-155.

COUTINHO, E. G. A comunicação do oprimido: malandragem, marginalidade e contra-hegemonia. In: RAQUEL, Paiva; CRISTIANO, Henrique. (orgs.). Comunidade e contra-hegemonia: rotas da comunicação alternativa. Rio de Janeiro: Mauad, 2008. p. 61-74.

COUTINHO, E. G. Comunicação e contra-hegemonia: processos culturais e comunicacionais de contestação, pressão e resistência. Rio de Janeiro: Editora UFRJ, 2008.

DUARTE, J. Entrevista em profundidade. In: DUARTE, J.; BARROS, A. (orgs.). Métodos e técnicas de pesquisa em comunicação. São Paulo: Atlas, 2009. p. 62-83.

HERSCHMANN, M.; GALVÃO, T. Algumas considerações sobre a cultura hip hop no Brasil hoje. In: BORELLI, Silvia; FREIRE FILHO, João (orgs.). Culturas juvenis no século XXI. São Paulo: EDUC, 2008. p. 195-210.

HERSCHMANN, M. O funk e o hip hop invadem a cena. Rio de Janeiro: UFRJ, 2005.

MAGNANI, José Guilherme Cantor. Da periferia ao centro: trajetórias de pesquisa em antropologia urbana. São Paulo: Terceiro Nome, 2012.

MAGNANI, José Guilherme Cantor. Quando o campo é a cidade: fazendo antropologia na metrópole. In: MAGNANI, José Guilherme Cantor; TORRES, Lilian de Lucca (orgs.). Na metrópole: textos de antropologia urbana. São Paulo: Editora da Universidade de São Paulo, 2000. p. 15 -53.

ROSE, Tricia (org.). Um estilo que ninguém segura: política, estilo e a cidade pós-industrial no hip hop. In: HERSCHMANN, Micael. Abalando os anos 90: funk e hip hop: globalização, violência e estilo cultural. Rio de Janeiro: Rocco, 1997. p. 190-214.

SALLES, Ecio. Poesia revoltada. Rio de Janeiro: Aeoroplano, 2007.
SOUZA, A. M. Globalizando localidades: relações de produção-consumo no movimento hip hop no Brasil e em Portugal. In: SOUZA, A. M.; RIAL, C. S.; SILVA, S. R. (orgs.). Consumo e Cultura Material: perspectivas etnográficas. Florianópolis: UFSC, 2012. p. 91-113.

\section{Recebido em 11/12/2017 Aprovado em 25/02/2018}

\begin{abstract}
I Amanda Rosiéli Fiuza e Silva. Mestranda em Comunicação Midiática pelo Programa de Pós-Graduação em Comunicação da Universidade Federal de Santa Maria, Rio Grande do Sul. Contato: rosieliamanda@gmail.com

II Sandra Rúbia da Silva. Doutora em Antropologia Social, pela Universidade Federal de Santa Catarina, professora do Programa de Pós Graduação em Comunicação da Universidade Federal de Santa Maria. Contato: sandraxrubia@gmail.com

III Jonária França da Silva, Doutoranda em Comunicação Midiática pelo Programa de Pós-Graduação em Comunicação da Universidade Federal de Santa Maria. Contato: jonariafranca@gmail.com
\end{abstract}

IV Termo utilizado para indicar que não são utilizados equipamentos de som e o beat box é feito com a voz.

V Entendemos comunicação dominante a partir das características dos meios de comunicação que alcançam públicos em larga escala e também aquelas produzidas pelos grandes conglomerados da mídia.

VI É a sigla ou marca que os grupos utilizam como assinatura.

VII Rima freestyle é o estilo livre que o MC tem para compor suas rimas, ou seja, sem a necessidade de seguir uma temática. 